\title{
A COMPENSAÇÃO AMBIENTAL DE CAVIDADES NATURAIS SUBTERRÂNEAS EM LICENCIAMENTO AMBIENTAL: A POSSIBILIDADE DE FIXAÇÃO DE CAVIDADE TESTEMUNHO POR IMPACTOS IRREVERSÍVEIS DE EMPREENDIMENTOS EM CAVIDADES SUBTERRÂNEAS DE GRAU DE RELEVÂNCIA MÉDIO

\author{
COMPENSATION OF ENVIRONMENTAL NATURAL UNDERGROUND \\ CAVITIES IN ENVIRONMENTAL LICENSING: THE HOLLOW OF FIXING THE \\ POSSIBILITY OF TESTIMONY FOR IMPACTS OF IRREVERSIBLE \\ DEVELOPMENTS IN UNDERGROUND CAVITIES DEGREE OF RELEVANCE \\ AVERAGE
}

${ }^{1}$ Dioclides José Maria

\section{RESUMO}

O presente estudo tem por objetivo analisar o Decreto n. 99.556 , de $1^{\circ}$ de outubro de 1990 com a redação atribuída pelo Decreto n. 6.640, de 7 de novembro de 2008 versando sobre proteção do patrimônio espeleológico. A hipótese é de aplicação da medida compensatória de preservação permanente de cavidades testemunho em empreendimentos de impactos irreversíveis de cavidades subterrâneas de grau de relevância médio. Mediante método qualitativo e ampla pesquisa bibliográfica, apresentou-se considerações sobre a possibilidade de preservação permanente de cavidades testemunho por impactos do empreendimento em cavidades naturais subterrâneas de grau de relevância médio.

Palavras-chave: Ambiental, Cavidades naturais, Compensação, Preservação

\begin{abstract}
This study aims to analyze the Decree. 99.556 of $10.1^{\circ} .1990$ with the wording given by Decree. 6640, of 11.07.2008 dealing on protection of speleological heritage. The hypothesis is application of compensatory measure of permanent preservation cavities testimony in irreversible impacts of projects of medium significance level of underground cavities. By qualitative method and bibliographic research, it presented considerations about the possibility of preserving permanently underground cavities testimony by project impacts on medium relevance degree of natural underground cavities.
\end{abstract}

Keywords: Environmental, Natural cavities, Compensation, Preservation

\footnotetext{
${ }^{1}$ Mestre em Direito Ambiental e Sustentabilidade pela Escola Superior Dom Helder Câmara em Minas Gerais Dom Helder, Minas Gerais (Brasil). Assessor Jurídico pela Secretaria de Estado da Defesa Social de Minas Gerais SEDS, Minas Gerais (Brasil). E-mail: dioclides_m@hotmail.com
} 


\section{INTRODUÇÃO}

As cavidades naturais subterrâneas compõem ecossistemas que apresentam condições ambientais exclusivas que revelam sua fragilidade e importância ambiental, especialmente quanto ao controle da qualidade, quantidade e periodicidade de oferta dos recursos hídricos, superficiais ou subterrâneos, e na manutenção e preservação de diversas espécies de vertebrados e invertebrados, dos quais vários se destacam com importante papel na dinâmica ambiental do meio hipógeo ou mesmo do meio epígeo.

As cavidades naturais subterrâneas apresentam relação com áreas vocacionadas à exploração econômica dos recursos naturais, principalmente extração de calcário e minério de ferro e em prol do desenvolvimento econômico acabam sofrendo impactos irreversíveis pelos empreendimentos que ensejam a adoção de medidas ambientais compensatórias.

A legislação ambiental brasileira conta com dois instrumentos básicos e diretamente vinculados à regulação do uso e à proteção do patrimônio espeleológico brasileiro: a Resolução CONAMA (Conselho Nacional do meio Ambiente), n. 347 de 2004, que destaca a importância de atributos ecológicos, ambientais, cênicos ou socioeconômicos na identificação do nível de relevância das cavidades; e o decreto $n^{\circ}$. 99.556/1990, alterado pelo decreto $\mathrm{n}^{\circ}$. 6.640/2008, que define os diferentes graus de relevância para fim de enquadramento das cavidades e os níveis de proteção a que estão sujeitas, estendendo-se da preservação a supressão de cavidades.

É no bojo do procedimento de licenciamento ambiental que o responsável pelo empreendimento ou atividade deve instruir esse procedimento com estudos espeleológicos que reúnam todas as informações pertinentes às cavidades e à sua área de influência, necessárias para que o órgão ambiental competente licenciador proceda à classificação do grau de relevância (máximo, alto, médio e baixo), bem como possa estipular as condições e medidas compensatórias à emissão da licença ambiental.

A compreensão da compensação por impactos irreversíveis de cavidades naturais subterrâneas perpassa pela análise da legislação nacional e do Estado de Minas Gerais relacionadas ao patrimônio ambiental espeleológico, bem como uma abordagem sobre o princípio do poluidor-pagador nas vertentes, preventiva e repressiva, como sucedâneo para análise e melhor compreensão da classificação de relevância das cavidades para determinar as medidas compensatórias. 
A Compensação Ambiental de Cavidades Naturais Subterrâneas em Licenciamento Ambiental: A Possibilidade de Fixação de Cavidade Testemunho por Impactos Irreversíveis de Empreendimentos em Cavidades Subterrâneas de Grau de Relevância Médio

A hipótese defendida seria a possibilidade de aplicação de medidas compensatórias de preservação permanente de cavidades testemunho em virtude de impactos irreversíveis de cavidades subterrâneas, porém, de grau de relevância médio, apesar de não haver previsão expressa no Decreto n. 99.556, de 1990.

Analisou-se a referência bibliográfica pesquisada, principalmente os conceitos de preservacionismo versus conservacionismo e mediante interpretação lógico-sistêmica do ordenamento legal, entendeu-se ser viável empreendimento impactante e irreversível de cavidades de grau de relevância médio, mediante aplicação pelo agente licenciador de medida compensatória de preservação permanente de cavidades naturais subterrâneas testemunho.

\section{CAVIDADES E PATRIMÔNIO AMBIENTAL ESPELEOLÓGICO}

O patrimônio espeleológico é o conjunto de ocorrências geológicas que formaram as cavidades naturais subterrâneas.

São exemplos de cavidades naturais vales fechados, dolinas, paredões verticais, canyons, sumidouros, abismos, drenagens subterrâneas, furnas, tocas, grutas, lapas e abrigos sob rochas, que são considerados bens da União a teor do disposto no art. 20, X, da Constituição Federal:

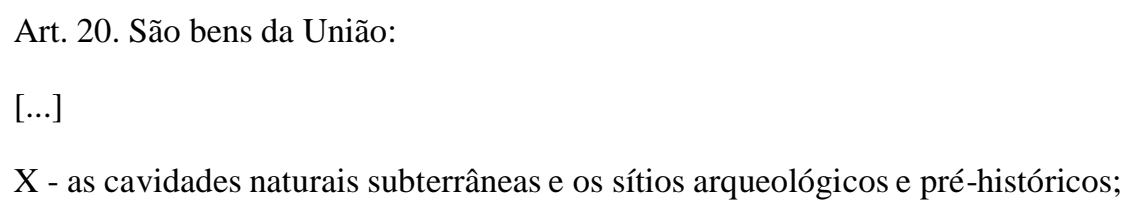

A proteção desses locais é de fundamental importância em razão de sua relevância para o meio ambiente natural e cultural. Com efeito:

[...] as cavidades naturais subterrâneas compõem ecossistemas de intensa
complexidade e de grande fragilidade ambiental, com significativo endemismo
faunístico, beleza cênica, multiplicidade de feições morfológicas, deposições minerais
de diversos formatos (espeleotemas) e estratégicos reservatórios de água, além de
comumente guardarem vestígios paleontológicos (p. ex., megafauna extinta),
arqueológicos (p. ex., pinturas rupestres e sepultamentos pré-históricos) e de
mudanças climáticas (paleoclima), de fundamental importância para melhor
compreensão da evolução da vida sobre a Terra (MIRANDA, 2009, p. 54).

Com isso, nunca é demais relembrar que, a Constituição de 1988, em seu art. 225, dispõe que o meio ambiente saudável e equilibrado é um direito e dever de todos, das 
gerações atuais e futuras, sendo que para alguns se constitui em "um verdadeiro direito fundamental ao ambiente ecologicamente equilibrado" (COELHO, 2014, p. 59).

Segundo essa premissa, a Constituição do Estado de Minas Gerais, reconhecendo a importância da preservação do patrimônio espeleológico existente em seu território, estabeleceu no art. 214 que Todos têm direito a meio ambiente ecologicamente equilibrado e que Estado e à coletividade é imposto o dever de defendê-lo e conservá-lo para as gerações presentes e futuras.

A Lei Estadual nº 11.726, de 1994, que dispõe sobre a política cultural de Minas Gerais, dispõe em seu art. 13 que Os bens e sítios arqueológicos, as cavidades naturais subterrâneas e os depósitos fossilíferos sujeitam-se à guarda e proteção do Estado, que as exercerá em colaboração com a comunidade. A mesma Lei, em seu artigo 14, inciso III definiu as cavidades naturais subterrâneas como sítios arqueológicos, especificando-as no parágrafo único como sendo as cavernas, grutas, lapas, furnas ou assemelhados, formados por processos naturais, incluídos o seu conteúdo mineral e hídrico, o corpo rochoso em que estejam inseridos e as comunidades bióticas abrigadas em seu interior. E no art. 15 tratou de dispor sobre a atividade econômica exploratória de qualquer natureza, obras bem como a realização de obra de infra-estrutura e a construção em área identificada como de interesse arqueológico, espeleológico ou paleontológico, para exigir a realização de estudo prévio de impacto cultural e da aprovação, pelo Conselho Estadual de Cultura, do respectivo relatório de impacto cultural, observado o disposto nos $\S \S 1^{\circ}, 2^{\circ}$ e $3^{\circ}$ do art. 10 da mesma Lei.

Há evidente tratamento específico e peculiar aos sítios espeleológicos de Minas Gerais, como espaços territoriais especialmente protegidos. Especificamente, o art. $2^{\circ}$ da Lei Estadual $n^{\circ} 18.043 / 2009$, que modifica o Decreto $n^{\circ} 20.597$, de 4 de junho de 1980, que define área de proteção especial, situada nos Municípios de Lagoa Santa, Pedro Leopoldo e Matozinhos, para fins do disposto no art. 13 da Lei Federal nº 6.766, de 19 de dezembro de 1979.

As áreas de rochas solúveis que integram o denominado relevo cárstico, exige proteção elevada segundo melhor explanação técnico/científica:

Destaca-se que a literatura espeleológica específica registra que as definições mais modernas evitam ligar o termo 'carste' a uma litologia específica ou a rochas carbonáticas em especial, uma vez que a gênese de algumas ocorrências espeleológicas não estaria ligada necessariamente à dissolução das rochas. HART, Rubens. Carste em arenito: considerações gerais. Anais do XXVII Congresso Brasileiro de Espeleologia. 2003, p. 163-167. 
A Compensação Ambiental de Cavidades Naturais Subterrâneas em Licenciamento Ambiental: A

Entretanto, originariamente a palavra carste está ligada a uma região calcária na atual Eslovênia, onde foram realizados os primeiros estudos neste tipo de rocha. O termo local é kras, que foi germanizado para karst. Em servo-croata, carste designa "campo de pedras calcárias" e atualmente é adotada para qualquer região do mundo que possua características semelhantes à da região do "carste clássico" (MIRANDA, 2012, p. 60)

O Atlas para Conservação da Biodiversidade em Minas Gerais, elaborado pela Fundação Biodiversitas, ao reconhecer o relevo cárstico como área de extrema vulnerabilidade, recomendou, inclusive, exigir que no licenciamento ambiental de atividades modificadoras do meio ambiente a serem desenvolvidas em áreas de ocorrência de rochas solúveis, exija-se avaliação específica de seus impactos sobre o patrimônio espeleológico nelas existente, expressamente:

Exigir, no licenciamento ambiental de atividades modificadoras do meio ambiente a serem desenvolvidas em áreas de ocorrência de rochas solúveis, avaliação específica de seus impactos sobre o patrimônio cultural, arqueológico, paleontológico e espeleológico nelas existente;

\begin{abstract}
Subordinar as autorizações ambientais, em especial o licenciamento ambiental e a outorga de uso da água para o desenvolvimento de atividades modificadoras do meio ambiente em áreas de ocorrência de rochas solúveis, a estudo prévio que demonstre a viabilidade ambiental da intervenção e avalie seus impactos sobre o aquífero cárstico. Tal estudo deverá necessariamente: a) estabelecer a recarga do aquífero cárstico por meio de técnicas de hidrogeologia; b) estabelecer a possível existência de vazios endocársticos por meio dos métodos e técnicas de geofísica aplicáveis; c) verificar a capacidade de explotação de água do sistema cárstico; d) limitar as interferências sobre o aquífero à capacidade de explotação do sistema cárstico. (DRUMMOND et al, 2005, p. 196-197).
\end{abstract}

Inegável a relevância que o ordenamento jurídico nacional e especialmente o do Estado de Minas Gerais, atribuíram ao patrimônio espeleológico, o que exige do órgão competente pelo licenciamento, cuidado e empenho no momento de conceder licença ao proponente do projeto de empreendimento impactante de cavidades naturais subterrâneas. Espera-se, com isso, que, de alguma maneira, sejam fixadas medidas compensatórias que consigam, de alguma forma, minimizar os impactos negativos, sobre o meio ambiente decorrente da atividade econômica.

\title{
3 COMPENSAÇÃO DOS IMPACTOS NEGATIVOS IRREVERSSÍVEIS EM CAVIDADES NATURAIS SUBTERRÂNEAS
}

Uma das condições trazidas pelo Decreto n. 6.640/2008 para a concessão das licenças ambientas a empreendimentos e atividades geradores de impactos negativos irreversíveis sobre cavidades naturais subterrâneas, é a adoção de medidas compensatórias. Mas, 
antes de adentrar ao estudo das compensações cavernícolas, importante recordar os fundamentos das compensações ambientais em geral a partir do princípio do poluidor-pagador (PPP).

\subsection{Compensação e princípio do poluidor-pagador (PPP)}

Referido princípio, para alguns, foi concebido em 1972, pelo Conselho da Organização para Cooperação e Desenvolvimento Econômico - OCDE, na "Recomendação do Conselho sobre os Princípios Orientadores dos Aspectos Econômicos Internacionais das Políticas Ambientais"1

As preocupações que motivaram a elaboração do PPP eram eminentemente econômicas e englobava o seguinte:

1) Os recursos ambientais são geralmente limitados e seu emprego nas atividades de produção e consumo pode levar a sua deterioração;

2) Quando o custo dessa deterioração, denominado "custo ambiental", não é adequadamente levado em conta na formação dos preços, o mercado falha para refletir a escassez de tais recursos, tanto no nível nacional quanto no internacional;

3) Faz-se necessária a adoção de políticas públicas para reduzir a poluição e alcançar uma melhor alocação de recursos, por meio da garantia de que os preços dos bens, dependendo da qualidade/e ou quantidade dos recursos ambientais, reflitam mais proximamente sua relativa escassez, com a cooperação dos agentes econômicos envolvidos;

4) As políticas ambientais das diversas nações deveriam ser, sempre que possível, harmônicas, no que diz respeito ao seu rigor e aos cronogramas de implantação, sob pena de levarem a distorções de competitividade no comércio internacional (empresas instaladas em países com leis mais brandas gastariam menos no combate à poluição, e, assim, usufruiriam de vantagens competitivas). (SOUZA, 2012, p. 156)

Em outras palavras, percebeu-se que o modelo de produção e consumo estava gerando reflexos indesejados do ponto de vista econômico-ambiental (escassez de recursos ambientais necessários ao desenvolvimento econômico e poluição). Tais falhas de mercado são conhecidas como externalidades negativas:

Durante o processo produtivo, além do produto a ser comercializado, são produzidas "externalidades negativas". São chamadas externalidades porque, embora resultantes

\footnotetext{
${ }^{1}$ Tradução livre. No original: "Recommendation of the Council on Guiding Principles concerning International Economic Aspects of Environmental Policies".
} 
A Compensação Ambiental de Cavidades Naturais Subterrâneas em Licenciamento Ambiental: A

da produção, são recebidas pela coletividade, ao contrário do lucro, que é percebido pelo produtor privado. Daí a expressão 'privatização de lucros e socialização de perdas', quando identificadas as externalidades negativas. (DERANI, 2007, p. 142)

O ideal é que as externalidades negativas fossem combatidas de maneira harmônica pelos diversos países, sob pena de se criarem outros desarranjos, relacionados à competividade internacional.

O PPP, em suma, visa à internalização das externalidades negativas, ou seja, a fazer com que o custo ambiental seja incluído no preço do produto, de modo a evitar que os ônus decorrentes da produção e do consumo sejam transferidos do poluidor para a sociedade, principalmente para as pessoas que sequer tem acesso aos bens produzidos, e, portanto, não contribuem, ainda que indiretamente, para as externalidades negativas.

O princípio 16 da Declaração do Rio² adotou o PPP, ao dispor que:

[...] as autoridades nacionais devem procurar promover a internalização dos custos ambientais e o uso de instrumentos econômicos, tendo em vista a abordagem segundo a qual o poluidor deve, em princípio, arcar com o custo da poluição, com a devida atenção ao interesse público e sem provocar distorções no comércio e nos investimentos internacionais.

Esse princípio atua nas vertentes preventiva e repressiva. Nesta, o princípio incide depois de já consumado o dano ao meio ambiente e impõe a quem lhe deu causa a obrigação de repará-lo integralmente, tanto no que se refere à degradação como na reparação dos prejuízos suportados individualmente por cada vítima da poluição. Na vertente preventiva, o PPP preconiza uma ação antecipada à degradação da qualidade ambiental, evitando-a ou minimizando-a.

Importante salientar que o PPP na sua modalidade repressiva alcançou seu ponto culminante na Constituição Federal de 1988:

\begin{abstract}
Mas a força desse princípio, no que se refere à sua modalidade repressiva, alcançou seu ponto culminante na Lei Maior de 1988, primeiro diploma constitucional pátrio a consagrá-lo. Nela, ele encontra visível amparo no $\S 2^{\circ}$ do art. 225, que impõe aos mineradores a obrigação de recuperar o meio ambiente lesado, e, sobretudo, no $\S 3^{\circ}$ do mesmo artigo, que estende ao acusador de qualquer espécie de dano ambiental a obrigação de repará-lo. (SOUZA, 2012, p. 159)
\end{abstract}

Trata-se de obrigação de reparar o dano integralmente, a partir da melhor interpretação que se faz da norma constitucional bem como do artigo $14, \S 1^{\circ}$, da Lei n. 6.938, de 1981, que nos dizeres de Leite, "não restringiram a extensão da reparação" (2011, p. 227).

\footnotetext{
${ }^{2}$ Foi elaborada por ocasião da Conferência das Nações Unidas sobre Meio Ambiente e desenvolvimento, também conhecida como Rio-92 ou ECO-92.
} 
Uma das formas de reparação é a restauração, que "consiste em reconduzir o meio ambiente, do modo mais próximo possível, ao estado existente antes da degradação (recondução ao status quo ante)" (SOUZA, 2012, 159).

A doutrina majoritária é no sentido de que a restauração é a maneira mais eficiente de reparar o meio ambiente, exatamente por ser a que melhor restitui, tanto quanto possível, o valor ambiental subtraído pela degradação.

Desse modo, somente quando não for possível restaurar, ou seja, quando estiver diante um impacto negativo irreversível, cumprir-se-á empregar alguma outra forma de reparação, no caso, a compensação (compensação ecológica, aqui incluída a recuperação) e a indenização (compensação pecuniária).

Mostra-se eventualmente necessário cumular a restauração com a compensação ou a indenização. Tal medida será necessária quando houver razoável lapso temporal entre o advento do dano e a integral reparação, obstando à coletividade os serviços ambientais nas mesmas condições de antes da degradação, sendo que "esse prejuízo coletivo é também conhecido como dano ambiental interino, dano ambiental intercorrente, ou lucros cessantes ambientais" (SOUZA, 2012, 151).

Conforme Bechara, o instituto da compensação:

[...] tem por escopo 'aliviar' as consequências de um prejuízo causado ao meio ambiente por intermédio de um benefício ambiental que, em termos valorativos, tenha um significado e um 'tamanho' muito próximo ao da perda. (BECHARA, 2009, p. 137)

Vale dizer, a compensação ambiental seria a substituição do valor ambiental perdido por outro, de importância ambiental equivalente.

Mas não há unanimidade na doutrina sobre tal diferenciação. Há quem entenda, a partir do princípio da responsabilidade contido no art. $14, \S 1^{\circ}$, da Lei 6.938 , de 1.981 , que a compensação "é uma forma de indenização" (MACHADO, 2006, p. 237).

A indenização, a seu turno, é meio de reparação. Consiste no pagamento de uma quantia em dinheiro equivalente ao dano causado de interesse difuso, decorrente de sentença condenatória. Sua destinação será o fundo federal ou o estadual de reconstituição dos interesses difusos lesados, segundo art. 13, da Lei n. 7.347, de 1985:

Art. 13. Havendo condenação em dinheiro, a indenização pelo dano causado reverterá a um fundo gerido por um Conselho Federal ou por Conselhos Estaduais 
A Compensação Ambiental de Cavidades Naturais Subterrâneas em Licenciamento Ambiental: A Possibilidade de Fixação de Cavidade Testemunho por Impactos Irreversíveis de Empreendimentos em Cavidades Subterrâneas de Grau de Relevância Médio

de que participarão necessariamente o Ministério Público e representantes da comunidade, sendo seus recursos destinados à reconstituição dos bens lesados.

Com meio de reparação do dano ambiental, prefere-se a compensação à indenização em virtude das dificuldades envolvendo a quantificação em dinheiro do dano ambiental bem como em razão da incerteza sobre a reversão desses recursos do respectivo fundo para reparação interesse difuso ambiental afetado:

[...] Além disso, comparativamente à destinação de indenização ao fundo, a compensação permite uma reparação mais célere, e pode assegurar que o ganho ambiental se dê na mesma área degrada, nas suas imediações ou entorno. (SOUZA, 2012, p. 152).

A compensação ecológica pode assim ser entendida como um instituto, cuja finalidade é a reparação de danos ambientais irreversíveis, mediante substituição do bem ambiental perdido por outro de valor ambiental equivalente.

\subsection{Grau de relevância das cavidades subterrâneas}

Para melhor compreensão das medidas compensatórias cavernícolas, importa analisar o grau de relevância das cavidades subterrâneas, conforme previsão contida no Decreto n. 99.556, de 1990, com a redação atribuída pelo Decreto n. 6.640, de 2008.

Referido ato do poder executivo prevê em seu art. $2^{\circ}$ a classificação das cavidades naturais subterrâneas, segundo o grau de relevância dos impactos para fins de licenciamento, em máximo, alto, médio, ou baixo:

Art. $2^{\circ}$ A cavidade natural subterrânea será classificada de acordo com seu grau de relevância em máximo, alto, médio ou baixo, determinado pela análise de atributos ecológicos, biológicos, geológicos, hidrológicos, paleontológicos, cênicos, históricoculturais e socioeconômicos, avaliados sob enfoque regional e local. (Redação dada pelo Decreto ${ }^{\circ}$ 6.640, de 2008).

Importante salientar que as alterações trazidas pelo Decreto n. 6.640, de 2008 reduziu a proteção do patrimônio espeleológico brasileiro. Resta evidente que a norma trouxe apenas dois grupos de relevância para as cavidades naturais subterrâneas, quais sejam, as relevantes (grau máximo) e não relevantes (grau alto, médio e baixo) que podem ser suprimidas.

Diante dos riscos ao meio ambiente cavernícola, a comunidade jurídica não se quedou inerte:

Promotores de justiça, advogados e estudiosos do direito ambiental ressaltaram que o decreto alterou de maneira significativa o quadro de proteção do patrimônio espeleológico brasileiro, por redução do status protetivo. Esses autores consideraram essa alteração legal uma ameaça sem precedentes ao meio ambiente e ao patrimônio cultural do país. Reforçaram ainda que as origens dessa pressão de mudança são de 
caráter meramente econômico e político, desconsiderando valores constitucionalmente definidos, revelando um menosprezo ao princípio do desenvolvimento sustentável consagrado na Carta Magna e em outros documentos. (FIGUEIREDO, RASTEIRO, RODRIGUES, 2010, p. 55)

Nota-se de fato que com o advento do Decreto n. 6.640, de 2008 é possível vislumbrar um verdadeiro retrocesso socioambiental sempre combatido pela doutrina, dessa feita, em relação ao patrimônio espeleológico nacional:

\begin{abstract}
A aplicação do princípio da vedação de retrocesso para as questões ambientais afigurase indispensável na medida em que se verifica, sobretudo no brasil, preocupante tendência de flexibilização das normas de proteção ambiental, sob o argumento da necessidade de aceleração do crescimento econômico.(THOMÉ, 2014, p. 113)
\end{abstract}

Não obstante o retrocesso socioambiental verificado na norma verifica-se, também, inconstitucionalidade pela ausência de previsão de canais de participação com a comunidade no processo de proteção das cavernas e tratamento de matéria que deveria se dar em sede de lei e não por decreto:

\footnotetext{
Outro aspecto destacado como inconstitucional é a falta de canais de participação para a comunidade no processo de proteção das cavernas. Além disso, esse ato de revogação só poderia ter ocorrido por meio de lei específica, e não por decreto: ...(há evidente redução ou retrogradação do nível de proteção que, até então, revestia o patrimônio espeleológico brasileiro), o que também é vedado, pois a doutrina constitucionalista censura a aniquilação de conquistas protetivas, de forma que a tutela normativa deve se operar de modo progressivo no âmbito das relações jurídicas, a fim de não retroceder jamais a um nível de proteção inferior àquele já alcançado." (MIRANDA, 2009 apud FIGUEIREDO, RASTEIRO, RODRIGUES, 2010, p. 55)
}

Apresentadas as considerações alhures, adentra-se aos graus de relevância das cavidades naturais subterrâneas.

\title{
a) Cavidade com grau de relevância máximo
}

As cavidades de nível máximo de relevância seriam aquelas cujos atributos deverão ser classificados, conforme incisos do $\S 4^{\circ}$ do art. $2^{\circ}$ do Decreto n. 99.556, de 1990, em:

I - gênese única ou rara; (Incluído pelo Decreto nº 6.640, de 2008).

II - morfologia única; (Incluído pelo Decreto nº 6.640, de 2008).

III - dimensões notáveis em extensão, área ou volume; (Incluído pelo Decreto $\mathrm{n}^{\circ}$ 6.640, de 2008).

IV - espeleotemas únicos; (Incluído pelo Decreto nº 6.640, de 2008).

V - isolamento geográfico; (Incluído pelo Decreto nº 6.640, de 2008). 
A Compensação Ambiental de Cavidades Naturais Subterrâneas em Licenciamento Ambiental: A Possibilidade de Fixação de Cavidade Testemunho por Impactos Irreversíveis de Empreendimentos em Cavidades Subterrâneas de Grau de Relevância Médio

VI - abrigo essencial para a preservação de populações geneticamente viáveis de espécies animais em risco de extinção, constantes de listas oficiais; (Incluído pelo Decreto $\mathrm{n}^{\circ}$ 6.640, de 2008).

VII - hábitat essencial para preservação de populações geneticamente viáveis de espécies de troglóbios endêmicos ou relíctos; (Incluído pelo Decreto $n^{\circ} 6.640$, de 2008).

VIII - hábitat de troglóbio raro; (Incluído pelo Decreto nº 6.640, de 2008).

IX - interações ecológicas únicas; (Incluído pelo Decreto nº 6.640, de 2008).

$\mathrm{X}$ - cavidade testemunho; ou (Incluído pelo Decreto nº 6.640, de 2008).

XI - destacada relevância histórico-cultural ou religiosa. (Incluído pelo Decreto $\mathrm{n}^{\mathrm{o}}$ 6.640, de 2008).

§ 5o Para efeitos do $§ 40$, o atributo a que se refere seu inciso V só será considerado no caso de cavidades com grau de relevância alto e médio. (Incluído pelo Decreto $\mathrm{n}^{\circ}$ 6.640, de 2008).

Importante salientar que o atributo de isolamento geográfico integra a relevância cavernícola de alto e médio grau de relevância, sendo que a Administração, nesse caso, deverá "[...] baixar "ato normativo" enquadrando as cavidades nos respectivos graus de relevância" (ANTUNES, 2014, p. 1.218).

\section{b) Cavidade com grau de relevância alto}

A cavidade natural subterrânea com grau alto de relevância é aquela cuja importância de seus atributos seja considerada (i) acentuada sob enfoque local e regional; ou (ii) acentuada sob enfoque local e significativa sob enfoque regional, conforme norma do $\S 6^{\circ}$ do art. $2^{\circ}$ e $5^{\circ}$ do Decreto.

O empreendimento, nessa hipótese, deverá adotar medidas e ações de preservação permanente de duas cavidades naturais subterrâneas de "mesma litologia e com atributos similares à que sofreu o impacto, que serão consideradas cavidades testemunho" (SOUZA, 2012, p. 153).

A preservação dessas cavidades testemunhos ocorrerá em área contínua e no mesmo grupo geológico onde ocorreu o impacto ao meio ambiente, salvo, se na área afetada pelo empreendimento, não houver outras cavidades para serem classificadas como testemunho.

Nessa hipótese, o Instituto Chico Mendes de Conservação da Biodiversidade (ICMBio), “[...] poderá definir, de comum acordo com o empreendedor, outras formas de compensação (SOUZA, 2012, p. 153).

c) Cavidade com grau de relevância médio 
Conforme $\S 7^{\circ}$ do art. $2^{\circ}$ e $5^{\circ}$ do Decreto, cavidade natural subterrânea com grau de relevância médio é aquela cuja importância de seus atributos seja (i) acentuada sob enfoque local e baixa sob enfoque regional; ou (ii) significativa sob enfoque local e regional.

Nessa hipótese em que a cavidade natural subterrânea alcance grau de relevância médio, o órgão ambiental competente pelo licenciamento estipulará a compensação a ser implantada pelo empreendedor.

Referida compensação consistirá em medidas e financiamentos de ações que contribuam para a conservação e o uso adequado do patrimônio espeleológico, “[...] especialmente das cavidades naturais subterrâneas naturais com grau de relevância máximo e alto (SOUZA, 2012, p. 156).

\title{
d) Cavidade com grau de relevância baixo
}

A cavidade natural subterrânea com baixo grau de relevância, conforme $\S 8^{\circ}$ do art. $2^{\circ}, 4^{\circ}$ e $5^{\circ}$ do Decreto é aquela cuja importância de seus atributos seja considerada, (ii) significativa sob enfoque local e baixa sob enfoque regional; ou (ii) baixa sob enfoque local e regional.

Está disposto no $\S 5^{\circ}$ do artigo $4^{\circ}$ do Decreto que o empreendedor não está obrigado a adotar medidas e ações para assegurar a preservação de outras cavidades naturais, o que poderia induzir o interprete acreditar que o empreendedor estaria isento de medidas compensatórias nesse sentido, o que não seria compatível com o disposto no $\S 3^{\circ}$ do artigo 225 da Constituição:

\begin{abstract}
Com efeito, inexigir compensação dos impactos negativos irreversíveis sobre cavidades de baixo grau de relevância ofenderia nossa Carta Fundamental. É bem verdade que existem degradações ambientais que, por toleráveis, não chegam a corporificar um dano ambiental, e, portanto, não demandam reparação. Não parece ser o caso, porém, das degradações de que trata o artigo $4^{\circ}$ do decreto, que versa sobre impactos negativos irreversíveis. Ora, se são irreversíveis, configuram perturbações ambientais suficientes para quebrar o equilíbrio ambiental, consistindo, assim, degradações intoleráveis, danos ambientais, que, por imperativo constitucional (art. 225, § $3^{\circ}$ ), demandam reparação.
\end{abstract}

Há quem defenda inclusive que as medidas compensatórias aos impactos irreversíveis sobre as cavidades de baixa relevância podem ser exigidas do empreendedor na forma de condicionantes nas licenças ambientais, conforme exegese da norma do art. $8^{\circ}$ da Resolução CONAMA n. 237, de 1997: “Tais medidas compensatórias podem ser fixadas na forma dessas condicionantes" (SOUZA, 2012, p. 165). 
A Compensação Ambiental de Cavidades Naturais Subterrâneas em Licenciamento Ambiental: A Possibilidade de Fixação de Cavidade Testemunho por Impactos Irreversíveis de Empreendimentos em Cavidades Subterrâneas de Grau de Relevância Médio

Com essas considerações, tem-se que diante da impossibilidade da reparação de um dano ambiental por meio da restauração do meio cavernícola lesado, a compensação ambiental, sempre que tecnicamente viável, deve ser entendida como medida obrigatória, mesmo que o grau de relevância da cavidade natural subterrânea seja baixo.

\section{PRESERVAÇÃO PERMANENTE DE CAVIDADE TESTEMUNHO COMO COMPENSAÇÃO AMBIENTAL DE ATIVIDADES IMPACTANTES DE CAVIDADES DE GRAU MÉDIO}

A cavidade que ostenta grau de relevância médio enseja do órgão ambiental competente $^{3}$ determinar a compensação ao empreendedor. Esta consistirá em medidas e financiamentos de ações que contribuam para a conservação e o uso adequado do patrimônio espeleológico, principalmente das cavidades naturais subterrâneas com grau de relevância máximo e alto, conforme disposto no $\S 4^{\circ}$ do art. $4^{\circ}$ do Decreto n. 99.556, de 1990.

Importante observar que, em relação às atividades impactantes de cavidades de relevância alta, se exige medidas e ações para a preservação, em caráter permanente, de cavidades testemunho. Quanto às atividades impactantes de cavidades de relevância média há previsão na norma de fixação de medidas de financiamento de ações para a conservação e o uso adequado do patrimônio espeleológico brasileiro, especialmente das cavidades subterrâneas com grau de relevância máximo e alto.

Nota-se que enquanto o Decreto prevê expressamente a preservação para atividades impactantes de cavidades de relevância alta, em relação a atividades impactantes de cavidades de relevância média a compensação se dá na forma de conservação e uso adequado do patrimônio espeleológico brasileiro.

Apesar de ser sucinta a diferença, o questionamento que se faz é se seria lícito ao órgão ambiental competente estipular medida compensatória de preservação de cavidades

\footnotetext{
3 "Orgão ambiental competente" deve ser entendido como aquele responsável pelo licenciamento, ressalvando-se que o ICMBio, caso a cavidade situe-se em unidade de conservação federal ou sua zona de amortecimento, pode rever a classificação realizada pelo órgão licenciador, desde que haja, para tanto, fato novo, cientificamente fundado.
} 
testemunho para o licenciamento de empreendimento impactante de cavidades de grau médio, sem expressa previsão no Decreto n. 99.556, de 1990 ?

Apesar da medida prevista no Decreto apresentar-se razoável numa proporção de 2:1, carece-lhe, durante as fases do licenciamento ambiental, de “[...] um mecanismo claro de análise custo-benefício, inclusive do ponto de vista econômico, relacionado aos benefícios do projeto em relação à destruição da cavidade subterrânea natural. (ANTUNES, 2014, p. 1.220)

Como sabido, em nosso Direito Ambiental a preservação figura como espécie do gênero conservação. Sob o alvedrio científico, preservação e conservação seriam modos de proteção especial da natureza, "mas preservação representa a garantia integral da biota, enquanto a conservação, mais flexível, contenta-se em impor certos requisitos à exploração, dita sustentável, dos recursos naturais”. (BENJAMIN, 2001 apud SOUZA, 2012, p. 157)

A distinção entre preservação e conservação em relação ao meio ambiente encontra suas raízes nos Estados Unidos da América, no século XIX, numa concepção homem versus natureza, uma conservacionista e outra preservacionista.

\begin{abstract}
Uma delas ficou conhecida como conservacionista, e preconizava a "conservação dos recursos naturais", defendendo o uso adequado e criterioso de tais recursos. Tal pensamento, que teve em Gifford Pinchot seu maior expoente, foi o precursor do desenvolvimento sustentável, admitindo a utilização da natureza como recurso do homem, desde que sem comprometer as necessidades das gerações futuras. A outra linha protecionista, cujo teórico mais conhecido foi John Muir, foi denominada preservacionista, e advogava a reverência à natureza, cuja vida selvagem deveria ser apreciada estética e espiritualmente. Ela buscava a preservação pura da "natureza selvagem", com a criação de parques naturais livres de qualquer interferência humana. (DIEGUES, 2008 apud SOUZA, 2012, p. 158)
\end{abstract}

No Brasil, as influências dessas correntes de pensamento pode ser percebida na Lei n. 9.985, de 2000 que institui o Sistema Nacional de Unidades de Conservação da Natureza SNUC, estabelece critérios e normas para a criação, implantação e gestão das unidades de conservação.

\footnotetext{
Como se pode perceber da própria distribuição das categorias de manejo em grupos distintos, bem como de seus objetivos e diretrizes, a Lei n. 9.985/2000 reflete a composição de conflitos travados ao longo dos doze anos que levou, desde sua concepção, para ser editada, que abrangeram, dentre outros, embates dentro do próprio movimento ambiental, envolvendo preservacionistas e socioambientalistas. (LEUZINGER, 2008, p. 114).
}

Para alguns, a LSNUC tratou a preservação como espécie do gênero conservação, segundo o disposto nos incisos II e V do seu artigo $2^{\circ}$ :

Art. 2o Para os fins previstos nesta Lei, entende-se por: 
A Compensação Ambiental de Cavidades Naturais Subterrâneas em Licenciamento Ambiental: A

\section{$[\ldots]$}

II - conservação da natureza: o manejo do uso humano da natureza, compreendendo a preservação, a manutenção, a utilização sustentável, a restauração e a recuperação do ambiente natural, para que possa produzir o maior benefício, em bases sustentáveis, às atuais gerações, mantendo seu potencial de satisfazer as necessidades e aspirações das gerações futuras, e garantindo a sobrevivência dos seres vivos em geral;

$[\ldots]$

V - preservação: conjunto de métodos, procedimentos e políticas que visem a proteção a longo prazo das espécies, habitats e ecossistemas, além da manutenção dos processos ecológicos, prevenindo a simplificação dos sistemas naturais;

É possível perceber a partir do exame dos dispositivos que conservação abarca, entre os métodos, a preservação, sendo permitido concluir que a primeira é gênero do qual a segunda é espécie.

Feitas essas breves considerações, aborda-se o Decreto n. 99.556, de 1990 para aferirmos se trilhou os mesmos caminhos da LSNUC em relação a preservação como espécie e conservação como gênero.

Em uma primeira análise, percebe-se no Decreto, ao tratar dos impactos negativos irreversíveis sobre cavidades de alto grau de relevância, a adoção de medidas compensatórias de preservação permanente das cavidades testemunho. $\mathrm{O}$ empreendedor se incumbiria literalmente e por prazo indeterminado e em caráter irrevogável da proteção dessas cavidades naturais subterrâneas.

Mas quando o Decreto n. 99.556 de 1990 aborda os impactos em cavidades de graus médio de relevância, exige do empreendedor ações e medidas que contribuam para a conservação e uso adequado do patrimônio espeleológico. Observa-se que essas medidas não asseguram qualquer proteção em caráter permanente, não obstante a supressão de qualquer tipo de cavidade o seja, tudo em nome de um desenvolvimento econômico pouco preocupado com a sustentabilidade para as futuras gerações.

Obviamente que uma medida que assegure a preservação permanente de uma cavidade natural contribui para sua conservação. Mas noutro norte, nem toda medida que contribua para a conservação assegura a preservação perpétua da cavidade natural subterrânea.

Do pondo de vista lógico-gramatical, seria viável uma interpretação que estipule entre as medidas admissíveis nos $\S \S 1^{\circ}$ que trata da preservação e $\S 4^{\circ}$ que dispõe sobre 
conservação, do art. $4^{\circ}$ do Decreto, mantendo-se "uma relação de espécie e gênero" (SOUZA, 2012, p. 161).

Sob um prisma sistêmico-teleológico, tal método de interpretação permite conformar o Decreto à Constituição da República de 1988 no que tange à reparação do dano ambiental. Com isso, alguns afastam qualquer relação de preservação e conservação do Decreto com a LSNUC:

\begin{abstract}
A linha exegética defendida neste trabalho, ao vislumbrar na relação entre preservação e conservação do decreto em estudo uma interação do tipo espécie x gênero, afasta-a da clássica dicotomia preservacionista isolacionista $\mathrm{x}$ conservacionismo exploratório. Sem embargo, não se pode dizer que, no decreto, essa interação seja idêntica à LSNUC, em que a diferenciação entre preservação e conservação se dá com base nos usos admissíveis. (SOUZA, 2012, p. 162).
\end{abstract}

Desse modo, outros defendem solução alternativa em relação à tutela do patrimônio espeleológico no Brasil, considerando preservacionistas as medidas que assegurem a proteção das cavidades em caráter permanente e conservacionistas as que contribuem de alguma outra forma permanente ou não.

Para os defensores dessa corrente, poderá o órgão licenciador, mesmo quando se tratar de cavidade de grau de relevância médio, estipular obrigação de preservação, em caráter permanente, de cavidade testemunho, ou outras espécies de medidas de conservação de cavidades, de caráter não permanente, observando-se a determinadas ressalvas caso se opte pelas medidas de preservação em caráter permanente como compensação por impactos irreversíveis sobre cavidades de grau médio:

a) O licenciador deve satisfazer-se com a preservação de cavidades que possuam atributo caracterizador de grau de relevância médio. Desse modo, mantémse simetria e proporcionalidade em relação às compensações aplicáveis aos impactos sobre cavidades de alto grau de relevância, que exigem que as cavidades testemunho tenham, também, grau de relevância alto;

b) Não podem ser escolhidas, para cavidades testemunho, aquelas de grau de relevância máximo, uma vez que elas já são protegidas, pelo próprio decreto, pela impossibilidade de sofrer impactos negativos irreversíveis. Logo, sua preservação em caráter permanente, a título de compensação, não representaria o mesmo benefício ao patrimônio espeleológico que a elevação de uma de grau médio à condição de testemunho, já que, sem tal providência, ela continuaria passível de destruição. Logo, para que se veja alguma utilidade na referência às cavidades de relevância máxima feita no $\S 4^{\circ}$ do art. $4^{\circ}$, presume-se que a elas possam ser destinadas, tão somente, medidas de compensação de caráter não permanente em favor de um gestor público, como, por exemplo, doação a unidade de conservação de domínio público que contemple cavidade dessa natureza. (SOUZA, 2012, p. 162)

Entendemos, portanto, ser permitido ao órgão licenciador competente, sem prejuízo de outras medidas compensatórias previstas no Decreto n. 99.556, de 1990, quando se tratar 
A Compensação Ambiental de Cavidades Naturais Subterrâneas em Licenciamento Ambiental: A Possibilidade de Fixação de Cavidade Testemunho por Impactos Irreversíveis de Empreendimentos em Cavidades Subterrâneas de Grau de Relevância Médio

de impactos irreversíveis, de cavidade de grau de relevância médio, estipular obrigação de preservação, em caráter permanente, de cavidade testemunho.

\section{CONSIDERAÇÕES FINAIS}

O patrimônio espeleológico, enquanto conjunto de ocorrências geológicas que formaram as cavidades naturais subterrâneas é considerado bem da União e recebeu do ordenamento legal, especialmente do Estado de Minas Gerais, de relevância para o meio ambiente natural e cultural.

A compreensão da compensação ambiental perpassa pela análise do princípio do poluidor-pagador (PPP) visa à internalização das externalidades negativas, ou seja, a fazer com que o custo ambiental seja incluído no preço do produto, de modo a evitar que os ônus decorrentes da produção e do consumo sejam transferidos do poluidor para a sociedade, principalmente para as pessoas que sequer tem acesso aos bens produzidos, e, portanto, não contribuem, ainda que indiretamente, para as externalidades negativas.

O PPP atua na vertente repressiva quando incide depois de já consumado o dano ao meio ambiente e impõe a quem lhe deu causa a obrigação de repará-lo integralmente. Na vertente preventiva, o PPP preconiza uma ação antecipada à degradação da qualidade ambiental, evitando-a ou minimizando-a. Importante salientar que o PPP, na sua modalidade repressiva, alcançou seu ponto culminante na Constituição Federal de 1988, em seu art. 225,

$\S \S 2$ e $3^{\circ}$, quando impõe aos mineradores a obrigação de recuperar o meio ambiente lesado, e, sobretudo, a obrigação de reparar qualquer espécie de dano ambiental, respectivamente.

Uma das formas de reparação é a restauração, consistente na recondução do meio ambiente ao modo mais próximo possível ao estado existente antes da degradação, sendo que a doutrina majoritária é no sentido de que a restauração é a maneira mais eficiente de reparar o meio ambiente, exatamente por ser a que melhor restitui, tanto quanto possível, o valor ambiental subtraído pela degradação.

Somente quando não for possível restaurar, ou seja, quando estiver diante um impacto negativo irreversível, cumprir-se-á empregar alguma outra forma de reparação, no caso, a compensação ou a indenização. 
A compensação ecológica pode assim ser entendida como um instituto, cuja finalidade é a reparação de danos ambientais irreversíveis, mediante substituição do bem ambiental perdido por outro de valor ambiental equivalente.

O Decreto n. 99.556, de 1.990, com a redação atribuída pelo Decreto n. 6.640/2008, trata da concessão das licenças ambientas a empreendimentos e atividades geradores de impactos negativos irreversíveis sobre cavidades naturais subterrâneas e medidas compensatórias, conforme classificação de relevância das cavidades naturais subterrâneas.

Não obstante as diversas classificações trazidas pelo Decreto em relação aos impactos de cavidades naturais subterrâneas, o que se percebe é uma divisão dualista de relevância e reducionista do grau de proteção do patrimônio espeleológico brasileiro, quais sejam, as relevantes de grau máximo e não relevantes de grau alto, médio e baixo, que podem ser suprimidas.

O Decreto apresenta classificação de relevância de impacto de cavidades naturais subterrâneas em quatro níveis: máximo, alto, médio e baixo. No nível máximo, a cavidade estará protegida e não poderá sofrer qualquer tipo de impacto irreversível. Já no nível alto de relevância, o empreendimento deverá adotar medidas e ações de preservação permanente de duas cavidades naturais subterrâneas de mesma litologia e com atributos similares à que sofreu o impacto, que serão consideradas cavidades testemunho. A cavidade natural subterrânea que alcance grau de relevância médio, o órgão ambiental competente pelo licenciamento estipulará a compensação a ser implantada pelo empreendedor na forma de financiamentos de ações que contribuam para a conservação e o uso adequado do patrimônio espeleológico. Já a cavidade de grau baixo, o empreendedor não estaria obrigado a adotar medidas e ações para assegurar a preservação de outras cavidades naturais, todavia, tal interpretação malfere o disposto no $\S 3^{\circ}$ do artigo 225 da Constituição, devendo ser exigida compensação na forma de condicionantes nas licenças ambientais, conforme exegese da norma do art. $8^{\circ}$ da Resolução CONAMA n. 237, de 1997.

Como solução ao problema de ser lícito ao órgão ambiental competente estipular medida compensatória de preservação de cavidades testemunho para o licenciamento de empreendimento impactante de cavidades de grau médio, sem expressa previsão no Decreto n. 99.556, de 1990, após digressões sobre a ausência de mecanismos de análise de custosbenefícios das cavidades impactadas durante o licenciamento e diferenciações necessárias entre preservação e conservação, apresentou-se como solução a possibilidade de o órgão 
licenciador competente estipular obrigação de preservação, em caráter permanente, de cavidade testemunho, ou outras espécies de medidas de conservação de cavidades, de caráter não permanente, observando-se a determinadas ressalvas, por impactos irreversíveis de cavidades de grau médio de relevância.

\section{REFERÊNCIAS}

ANTUNES, Paulo de Bessa. Direito Ambiental. 16 ed. São Paulo: Editora Atlas, 2014.

BECHARA, Erika. Licenciamento e Compensação Ambiental na Lei do Sistema Nacional das Unidades de Conservação (SNUC). São Paulo: Atlas, 2009.

COELHO, Helena Carvalho. Do direito constitucional ao meio ambiente e desdobramentos principiológicos à hermenêutica (ambiental?) Veredas do Direito, Belo Horizonte, v.11, n.21, p.53-73, Janeiro/junho 2014.

DRUMMOND, Gláucia Moreira et al. Biodiversidade de Minas Gerais. 2 ed Belo Horizonte: Fundação Biodiversitas, 2005.

FIGUEIREDO, Luiz Afonso Vaz de. RASTEIRO, Marcelo Augusto. RODRIGUES, Pavel Carrijo. legislação para a proteção do patrimônio espeleológico brasileiro: mudanças, conflitos e o papel da sociedade civil. SBE - Campinas, SP | Espeleo-Tema. v. 21, n. 1, p. 49-65, 2010.

HART, Rubens. Carste em arenito: considerações gerais. Anais do XXVII Congresso Brasileiro de Espeleologia. 2003, p. 163-167.

LEITE, José Rubens Morato. AYALA, Patrick de Araújo. Dano Ambiental. Do individual ao coletivo extrapatrimonial. Teoria e prática. 4 ed. São Paulo: Revista dos Tribunais, 2011 .

LEUZINGER, Márcia Diegues. Natureza e cultura: criação de unidades de conservação de proteção integral e domínio público habitadas por populações tradicionais. Revista de Direito Ambiental. São Paulo: RT, n. 52 out/dez 2008.

MACHADO, Paulo Affonso Leme. Direito Ambiental Brasileiro. 15 ed. São Paulo: Malheiros, 2007.

MILARÉ, Edis. ARTIGAS, Priscila Santos. A proteção das cavidades naturais. Revista de Direito Ambiental. Ano 14, n. 54, abril-junho, 2009, p. 153-166.

MIRANDA, Marcos Paulo de Souza. Mineração em áreas de ocorrência de patrimônio espeleológico. MPMG Jurídico, Belo Horizonte, edição especial, 2012, p. 53-60.

SÁNCHEZ, Luis Enrique. Mineração e meio ambiente. In: FERNANDES, Francisco Rego C.; MATOS, Gerson M. M. de; CASTILHOS, Zuleica C.; LUZ, Adão Benvindo (ed.).

Tendências tecnológicas Brasil 2015: geociências e tecnologia mineral. Rio de Janeiro: SGB/CPRM/CETEM/MCT, 2007. 
SOUZA, Adriano Andrade. Tutela do Patrimônio Ambiental Espeleológico no Direito Material Brasileiro. Dissertação de Mestrado. São Paulo: Pontifícia Universidade Católica de São Paulo, 2012.

THOMÉ, Romeu. O princípio da vedação de retrocesso socioambiental no contexto da sociedade de risco. Bahia: Edita Podivm, 2014.

Competência para a proteção do patrimônio arqueológico e espeleológico brasileiro em procedimentos de licenciamento ambiental. In: Maria Lirida Calou de Araujo e Mendonça; Alexandre Coutinho Pagliarini; Sandro Marcelo Kozikoski.. (Org.). Direito Ambiental II (CONPEDI XXI). 1 ed. Florianópolis: FUNJAB, 2012, v. 1, p. 215-230. 